\title{
A modest proposal for future trials of medical treatment in inflammatory bowel disease
}

All concerned with the medical treatment of inflammatory bowel disease (Crohn's disease and ulcerative colitis) would agree that current drug treatments attempt to inhibit the biochemical chain of a multitude of inflammatory mediators. Most observers would also agree that these treatments leave much to be desired. In Crohn's disease, this point of view is reinforced by our recent meta analysis of 12 placebo controlled trials to determine the efficacy of a single drug either for induction (seven trials in 767 patients) or maintenance of remission (five trials in 796 patients). Current single drug treatment in this disease conferred an 11-27\% therapeutic advantage over placebo $(95 \% \mathrm{CI}=9$ to $31 \%)$ for the induction of remission, but no advantage for maintenance of remission. ${ }^{1}$ For comparison of single drug to placebo in mild to moderate ulcerative colitis, similar meta analyses of 11 trials (468 patients) for induction of remission, and of five trials (343 patients) for maintenance of remission again show the limitations of single drug treatment. ${ }^{2}$ The single drugs currently used conferred a therapeutic advantage of only $37-48 \%$ with similar results for maintenance of remission. In severe ulcerative colitis, our review of the defined clinical trials ${ }^{3}$ comprised five series of 248 therapeutic trials in 271 patients; understandably no single drug, placebo controlled trial has been condưcted in cases of severe ulcerative colitis. Remission in these severe cases was achieved by maximal medical treatment (intravenous steroids) in 59\% of patients $(95 \% \mathrm{CI}=52$ to $66 \%)$. Of the 205 patients in trials where colectomy was the predetermined end point of treatment failure, $35 \%$ lost their colons in the operating theatre.

We are well aware that the ideals of single drug trials and the abstractions of meta analysis are often far removed from the actualities of clinical practice. In both ulcerative colitis and Crohn's disease, failure to respond to the initial drug regimen leads to the addition of more drugs and failure at this stage may lead to the further addition of still more. Rather closer to actual practice in acute ulcerative colitis comes the recent report of the open study of Lichtiger and Present on the effect of adding cyclosporin to the regimen after intravenous steroids had failed to induce a remission. ${ }^{4}$

To these practical considerations, we must add the realisation that current drugs and even future drugs act at different steps in the inflammatory and immunological cascade by inhibiting the production, release or bio-activity of a number of mediators: leukotrienes, prostaglandins, interleukins, mast cell products, and neuropeptides, as well as free oxygen radicals. ${ }^{5}$ This concept certainly suggests that many points along the inflammatory or immunological chain need to be interrupted or suppressed if we are to improve the chances of therapeutic efficacy. Single drugs have not done the job in any but the milder to moderate cases of these diseases. We therefore propose that, as in the treatment of cancer, multiple drug chemotherapy should replace monotherapy to maximise the ability to achieve and maintain remission.

Further, although few controlled studies have stratified their cases according to initial attack $v$ relapse, it has been clear, since Truelove and Witts's classic study of cortisone in ulcerative colitis, that the response to treatment was better in first episodes than in relapses regardless of the severity. ${ }^{6}$

In light of these findings, we would make the following modest proposals regarding future therapeutic trials in inflammatory bowel disease: (1) A moratorium should be declared on any further trials of single agents unless the drug belongs to an entirely new class. (2) Future controlled trials should use two or more drugs acting at different loci in the inflammatory chain. (3) These multiple drugs should be used as early as possible in the attack.

Predetermined combinations of established drugs known to have some efficacy in these illnesses could be instituted at the onset of the initial episode, or else added to or substituted for those in place at the time of relapse. This proposal is consistent with the recent speculation of Rachmilewitz that at present 'there is little chance that a specific receptor antagonist or inhibitor of a single mediator of inflammation will be of therapeutic benefit'. ${ }^{7}$

While this paper was being prepared for publication, Kaplan has presented a similar view on the treatment of primary biliary cirrhosis urging trials of concomitant multiple drugs with some known efficacy in this disorder. Kaplan also bases his plea on the success of oncologists' as well as transplantation experts' use of multiple drugs. ${ }^{8}$

HENRY D JANOWITZ

Division of Gastroenterology,

Department of Medicine,

The Mount Sinai School of Medicine,

One Gustave Levy Place,

New York, NY 10029,

USA

This viewpoint has benefited from discussions with Dr Asher Kornbluth and Dr Charles Noyer.

1 Salomon P, Kornbluth A, Aisenberg J, Janowitz HD. How effective are current drugs for Crohn's disease? A meta-analysis. $f$ Clin Gastroenterol 1992; 14: 211-5.

2 Kornbluth A, Salomon P, Sacks HS, Mitty $\cdot R$, Janowitz HD. How effective are current drugs for ulcerative colitis? A meta-analysis. $\mathcal{F}$ Clin Gastroenterol 1993; 16: 215-8.

3 Kornbluth A, Salomon P, Janowitz HD. The efficacy of current medical therapy in severe ulcerative colitis. An analytic review of the defined trials [Abstract]. Am f Gastroenterol 1991; 86: 1356.

4 Lichtiger S, Present DH. Preliminary report: cyclosporine in treatment of severe active ulcerative colitis. Lancet 1990; 2: 16-9.

$5 \mathrm{McDermott} R \mathrm{R}$, Stenson WS. Alterations of the immune system in ulcerative colitis and Crohn's disease. Adv Immunol 1988; 42: 285-328.

6 Truelove SC, Witts LJ. Cortisone and ulcerative colitis. BMF 1955; 2: .

7 Rachmilewitz D. New forms of treatment for inflammatory bowel disease. Gut 1992; 33: 1301-2.

8 Kaplan MM. New strategies needed for treatment of biliary cirrhosis? Gastroenterology 1993; 104: 651-3. 